\title{
Trees Cannot Sequester Enough Carbon to Slow Abrupt Climate Change
}

ISSN: 2637-7659

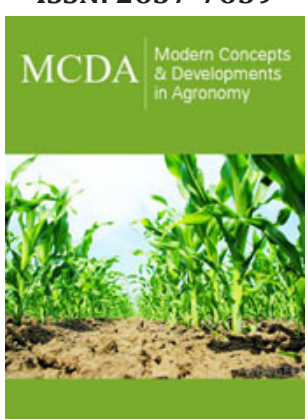

*Corresponding author: Guy R McPherson, Professor Emeritus of Conservation Biology, University of Arizona, USA

Submission: 悳 June 03, 2020

Published: 俔June 12, 2020

Volume 6 - Issue 4

How to cite this article: Guy R McPherson. Trees Cannot Sequester Enough Carbon to Slow Abrupt Climate Change. Mod Concep Dev Agrono. 6(4). MCDA. 000641. 2020 DOI: 10.31031/MCDA.2020.06.000641

Copyright@ Guy R McPherson, This article is distributed under the terms of the Creative Commons Attribution 4.0 International License, which permits unrestricted use and redistribution provided that the original author and source are credited.

\section{Guy R McPherson*}

Professor Emeritus of Conservation Biology, University of Arizona, USA

\begin{abstract}
The idea of planting trees to sequester atmospheric carbon is considered. Obviously, the process of photosynthesis insures that trees sequester carbon from the atmosphere. However, there are important questions that arise as we consider whether, how, and how many trees to plant. How fast do trees sequester carbon from the atmosphere? How much carbon do trees sequester? What negative side-effects are associated with planting large numbers of trees? These critical questions are addressed herein.
\end{abstract}

Keywords: Abrupt climate change; Carbon capture; Sequestration

\section{Introduction}

Earth is in the midst of abrupt and irreversible climate change [1]. Only by immediately halting all planetary deforestation can we convert forests from a global carbon source into a carbon sink. Considering the self-reinforcing feedback loops already triggered [2], it might be too late even for this radical action. In addition, the assumption that we will immediately halt all deforestation runs contrary to recent societal conduct and global trends. As of July, 2019, the Amazon basin alone was being deforested at the rate of 1 hectare per minute [3]. By June, 2020, more than 6 hectares per minute of rainforest were being destroyed, with Brazil accounting for more than one-third of the loss [4].

\section{Evidentiary Overview}

There is a nearly perfect match between an organism and its environment. The environment is comprised of everything that influences the life of an organism, including sunlight, climate, geology, and surrounding organisms. As a result of this close correspondence between an organism and its environment, minor environmental changes can produce profound changes in organisms, including loss of habitat for some species. In other words, the organism-any organism-depends upon a wide variety of factors for its continued persistence in a specific location (and therefore, on Earth). Loss of a seemingly minor species can therefore cascade into loss of habitat for a large number of species, thus leading to co-extinctions.

Co-extinctions result from a change in environmental conditions and the interdependency of organisms, with models indicating that a 5-6C global-average rise in temperature over the next century will lead to the loss of all life on Earth [5]. We have already eclipsed the muchvaunted target of $2 \mathrm{C}$, and we are clearly headed for at least a $6 \mathrm{C}$ rise in temperature within the coming few years, as described by McPherson $[1,2]$.

Planting trees in urban areas is not a viable means by which to sequester carbon [6]. For example, a Vancouver neighborhood sequestered about 1.7 percent as much carbon as human activities produced, while in Mexico City the figure was 1.4 percent. The results were worse in Singapore. Overall, the authors concluded, "The impact of urban vegetation to reduce greenhouse gas emissions directly through carbon sequestration is very limited or null" [6].

If planting trees in urban areas is not a viable means by which to sequester carbon, then what about planting trees in non-urban areas? This question is addressed by [7], who found that the most effective place to plant trees with respect to climate change is in the tropics 
and subtropics. Most forest-restoration commitments are found in these areas. In addition, trees sequester carbon relatively quickly near the equator, and land is inexpensive and available compared to temperate regions. In addition, establishing forests near the equator has little effect on the albedo (reflectivity) of the land surface, in contrast to high latitudes where trees obscure snow that would otherwise reflect incoming sunlight and therefore help keep the planet cool. Well-managed forests in the tropics and subtropics provide additional benefits, including helping alleviate poverty in low-income regions, conserving biological diversity, and supporting the United Nations Sustainable Development Goals.

The Intergovernmental Panel on Climate Change (IPCC) suggests in its October, 2018 report that atmospheric carbon sequestration by 2100 must total about 730 billion tonnes of $\mathrm{CO}_{2}$ (730 petagrams of $\mathrm{CO}_{2}$, or 199 petagrams of carbon, $\mathrm{Pg} \mathrm{C}$ ) [8,9]. In the near term, this means adding up to 24 million hectares (Mha) of forest every year between now and 2030. These 24 Mha of forest would be comprised of plantations. This is equivalent to all the $\mathrm{CO}_{2}$ emitted by the United States, the United Kingdom, Germany, and China since the Industrial Revolution began in 1750. There is no known means to capture so much atmospheric $\mathrm{CO}_{2}[1]$.

Fast-growing trees within plantations, such as Eucalyptus and Acacia, sequester up to 5 tonnes of carbon per hectare per year [10]. After such trees are harvested and the land is cleared for replanting - typically once per decade - the carbon is released into the atmosphere through decomposition. In other words, planting trees into plantations is a temporary measure. Worse yet, "afforestation projects... would be counterproductive if implemented at high latitudes and would offer only marginal benefits in temperate regions" [10].

Recognizing the inability of tropical and subtropical plantations to rise to the challenge posed by IPCC goals, "restoration community, forestry experts, and policymakers [are asked] to prioritize the regeneration of natural forests over other types of tree planting - by allowing disturbed lands to recover to their previous high-carbon state" [8]. This task "will entail tightening definitions, transparently reporting plans and outcomes and clearly stating the trade-offs between different uses of land" [8]. The clear conclusion is that restoration of extant forests, along with reforestation of deforested areas, is the most effective strategy for storing carbon. Examples have been demonstrated with restoration in tropical Indonesia [11] and, more recently, an overview of tropical systems focused on mitigation $[12,13]$.

Carbon-storage potential is currently being sabotaged by clashing global priorities. The best-case scenario offered by Lewis et al. [8] has the entire area available to management regenerating to natural forest. However, even under this unlikely scenario, only 42Pg of carbon would be stored in tropical and subtropical ecosystems by 2100 (vs. the stated goal of 199Pg).

\section{Other Considerations}

In addition to technical obstacles directly related to the task of planting trillions of trees, other issues must be considered. For example, the economic cost of managing forests must be paid. By whom? Under what set of contracts? Who would derive financial benefits under these contracts? In addition to these financial concerns, at least three additional issues must be addressed: ongoing overheating of Earth, the aerosol masking effect, and the environmental consequences of water uptake by trees. According to a major, synthetic overview published by European Strategy and Policy Analysis System, an "increase of 1.5 degrees is the maximum the planet can tolerate; ... at worst, [such a rise in temperature above the 1750 baseline will cause] the extinction of humankind altogether" [10]. In other words, according to this synthesis, we have passed the point beyond which human extinction is likely to occur. After all, Earth is currently at least 2C above the 1750 baseline $[1,2]$.

There is no known means to rapidly stabilize or cool the temperature of Earth. However, there are several means by which the planet can be quickly, additionally overheated [2]. Any one of these means could cause an abrupt loss of habitat for human, animals on Earth. After all, wet-bulb temperatures lethal for humans already have been reported, despite climate-change models indicating that such an event would not occur until the middle of the current century [10]. In the wake of SARS-CoV-2, loss of aerosol masking as industrial activity declines has been described as a trigger for the rapid extinction of all life on Earth [2]. Finally, planting trees reduces surface water. Several studies have linked increased forest cover with reduced river flow and potentially detrimental effects downstream [14]. A meta-analysis of 43 published studies found that forests reduced annual river flow by $23 \%$ after 5 years and $38 \%$ after 25 years [14]. These adverse effects persisted for five decades after forests became established.

\section{Conclusion}

I am not proposing "giving up," whatever that means in the midst of the SARS-CoV-2 pandemic, the ongoing Mass Extinction Event, and abrupt, irreversible climate change. The ongoing Mass Extinction Event, underlain by human actions, indicates that we have lost the battle for human habitat on Earth. As I have indicated, loss of habitat for our species looms on the near horizon, with no known means of avoiding extinction. The actions we take from this point indicate our character, as individuals and as a species, as we exit Earth. Rather than giving up, my ongoing scholarly efforts are focused on minimizing suffering $[15,16]$. How do we minimize suffering? Is such a quest restricted to humans, or are other organisms included? What is the temporal frame of the quest? Does it extend beyond the moment, perhaps to months or years? Does it extend beyond the personal to include other individuals? These are the questions on which I believe it is fitting to focus. Perhaps others will join me in my quest to understand suffering and its causes. Perhaps doing so will alleviate further suffering. I can imagine worse pursuits.

\section{References}

1. McPherson GR (2020) Earth is in the midst of abrupt, irreversible climate change. Journal of Earth and Environmental Sciences Research 2(2): 1-2. 
2. McPherson GR (2020) Will COVID-19 trigger extinction of all life on earth? Earth \& Environmental Science Research \& Reviews 3(2): 73.

3. Shukman D (2019) Football pitch of Amazon forest lost every minute. BBC News, Brazil.

4. Hood M (2020) Football pitch of rainforest destroyed every six seconds. Phys Org.

5. Strona G, Bradshaw CJA (2018) Co-extinctions annihilate planetary life during extreme environmental change. Scientific Reports Vol8.

6. Velasco E, Roth M, Norford L, Molina LT (2016) Does urban vegetation enhance carbon sequestration? Landscape and Urban Planning 148: 99107.

7. Intergovernmental Panel on Climate Change (2018) Global Warming of $1.5^{\circ} \mathrm{C}$.

8. Lewis SL, Wheeler CE, Mitchard ETA, Kock A (2019) Restoring natural forests is the best way to remove atmospheric carbon. Nature 568: 2528.

9. Bala G, Caldeira K, Wickett M, Phillips TJ, Lobell DB, et al. (2007) Combined climate and carbon-cycle effects of large-scale deforestation, Proceedings of the National Academy of Sciences 104: 6550-6555.

10. Gaub L (2019) Global trends to 2030: Challenges and choices for Europe, European strategy and policy analysis system.
11. Budiharta S, Meijaard E, Erskine PD, Rondinini C, Pacifici M, et al. (2014) Restoring degraded tropical forests for carbon and biodiversity. Environmental Research Letters 9(11): 114020.

12. Mackey B, Kormos CF, Keith H, Moomaw WR, Houghton RA, et al. (2020) Understanding the importance of primary tropical forest protection as a mitigation strategy. Mitigation and Adaptation Strategies for Global Change.

13. Raymond C, Matthews T, Horton RM (2020) The emergence of heat and humidity too severe for human tolerance. Science Advances 6(19): eaaw1838.

14. Bentley LB, Coomes DA (2020) Partial river flow recovery with forest age is rare in the decades following establishment. Global Change Biology 26(3): 1458-1473.

15. McPherson GR (2019) Becoming hope-free: Parallels between death of individuals and extinction of Homo sapiens. Clinical Psychology Forum 317: 8-11.

16. McPherson GR (2019) Going halfway: climate reports ignore the full evidence, and therapists ignore grief recovery. Clinical Psychology Forum 321: 28-31. 